\author{
Siniša Vilke \\ E-mail: svilke@pfri.hr
}

Frane Tadić

E-mail: tadic@pfri.hr

University of Rijeka, Faculty of Maritime Studies, Studentska 2, 51000 Rijeka, Croatia

\title{
Review of Good Practices in the Introduction of Traffic Management Systems and Urban Mobility
}

\begin{abstract}
Mobility, as one of the most significant factors in maintaining the quality of life in cities, faces problems such as traffic congestion and environmental pollution. The rapid population growth in urban areas has had an impact on increased traffic, which is why many cities have decided to implement or improve existing intelligent transport systems (ITS) that reduce traffic congestion with more comfortable and safer pedestrian traffic. Although the population in developed and densely populated cities is familiar with multimodal transportation, inadequate urban transport systems and large individual transport in place continue to pose a major threat. The application of appropriate ITS systems manages traffic and mobility management that are present to residents and facilitate access to all forms of transport. The aim of this paper is to explore urban mobility examples of good traffic management practice for the possibility of their application in cities with issues such as traffic jams and accidents, low pedestrian safety, parking problems, etc.
\end{abstract}

Key words: urban mobility, traffic management systems, intelligent transport systems, sustainable transport

\section{Introduction}

Quality traffic management and urban mobility is one of the primary tasks of city authorities as it affects the quality of life of residents. Efficient and sustainable transport in urban areas often requires the introduction of additional ways of traffic management such as: public transport priorities, better conditions for non-motorized vehicles, realtime traffic information, etc. In order to fulfil these tasks, Intelligent Transport Systems (ITS) are being introduced that can efficiently and effectively manage the transport network, which ensures the smooth and safe flow of traffic. Systems are often a key 
tool of city traffic centres that upgrade the functionality of the existing traffic control using coordinated traffic signalization. Therefore, the implementation of such systems can meet city requirements such as increasing road safety, reducing air pollution, giving priority to certain road users, better control of urban areas and reducing traffic congestion caused by road works or traffic accidents. Urban Traffic Control (UTC) systems for determining traffic management strategy most often use real-time road conditions data.

Several studies such as "Handbooks in Operations Research and Management Science" [1] and "The evolution of urban traffic control: changing policy and technology" [2] point out that traffic control mainly acts on the supply side of the basic traffic equation. They also describe the various benefits of the UTC system such as reduced congestion, greater economic efficiency and improved road safety and air quality.

The problem of urban mobility is highlighted in the paper "Contemporary Issues of Urban Mobility" [3] where the main cause of traffic congestion is the rapid growth of individual transport and inadequate solutions of local transport systems.

The negative results of traffic jams are inherent in all cities, while the world's metropolises are most affected by this problem. As traffic jams prolong travel time, vehicles also consume more fuel which increases environmental pollution and reduces the quality of life of residents.

In addition to the slowdown in road traffic, another disadvantage of most urban areas is the finding of a parking space. Building parking lots in city centres is a difficult task given the lack of free space for construction and historical heritage in older cities.

The aim of this paper is to analyze examples of good traffic management practice to present possible solutions to the problem of urban mobility in cities. It further seeks to describe the impact of ITS on solving the problem of traffic jams, traffic accidents and environmental pollution.

\section{Problems of urban mobility in cities}

With the rapid growth and development of cities, urban mobility has reached its limits in certain areas. Economic progress is unachievable without efficient traffic flow as it connects places of production with places of consumption. Therefore, the need for mobility is constantly growing, which affects traffic congestion, congestion in public transport, reduced pedestrian safety, environmental pollution, and traffic accidents [4].

Efficient urban transport management contributes significantly to reducing environmental pollution and traffic congestion. This can be hampered by a large share of individual transport, inefficient transport routes and inadequate urban plans. In order to solve this problem, some cities have applied models such as city centre car-free, car sharing, rent a bike or scooter, etc. Furthermore, the problems of public transport in urban areas refer to high overcrowding of passengers in vehicles, bus or train stations, 
especially in peak hours. Also, in many cases the shortcoming can be highlighted in the inadequacy of public transport for example "if the public transport operator has a large enough fleet to cover peak demand, off-peak demand will not justify operations, meaning almost empty buses during "slow" times, leading to financial losses. On the other hand, if they adopt the fleet size to off-peak demand, there will not be enough vehicles for peak hours" [4].

Another problem that most of the world's metropolises face is the difficult movement of pedestrians due to heavy traffic of vehicles. Economically underdeveloped densely populated areas like Southeast Asia struggle with difficult pedestrian movement especially on narrow sidewalks that are not uncommon. Pedestrian problems in these areas are most prominent in [5]:

- Overcrowding along narrow footpaths,

- Difficulties in crossing the road at ground level,

- Poor signage, and barriers to pedestrian movement,

- An unwelcoming environment for the elderly and physically disabled,

- Safety problems in relation to traffic and in areas that are poorly lit or badly maintained,

- Noise and air pollution from traffic,

- Unattractive streets and pedestrian links which lack character, identity, and comfort (shade, seating, plants etc.).

Furthermore, "smart" cities use measures and strategies such as Vision Zero and the Car-free zone to encourage pedestrians to reduce vehicle use and turn to urban transport, cycling and walking [6].

Reducing environmental pollution caused by traffic is one of the primary goals of developed cities. Many vehicles in urban areas are impairing the quality of life of residents with noise and air pollution. Therefore, for the purpose of sustainable transport, i.e. mobility in urban areas, the policy tries to bring the alternative mode of transport closer to the users through various measures, which would, in addition to environmental pollution, also contribute to the reduction of traffic accidents.

Vehicle parking in city centres is also a great challenge to be resolved in urban areas. Due to the lack of parking spaces, vehicles pile up on the roads looking for a free space resulting in congestion. In some traffic management practices for such a scenario, traffic is limited to vehicles in the very centre of the city [7].

\section{Examples of traffic management in cities}

In this section some of the examples of good traffic management practices are described in order to highlight the problems faced by cities in terms of urban mobility and to apply the best solutions to issues such as traffic jams and accidents, urban parking problems or low pedestrian safety. 


\subsection{Dublin - RTPI (Real-time passenger information system)}

The Government of the Republic of Ireland, Department for Transport, Tourism and Sport, adopted in 2002 the decision to introduce $25 \%$ of private bus operators within two years, since until then public transport services had been provided exclusively by the state carrier. Therefore, with the arrival of private bus operators on the passenger transport market in the city of Dublin, the Transport Directorate of Dublin (DTA) ${ }^{1}$ has set standards for services such as the introduction of multiple ITS or the Real-Time Passenger Information Monitoring System (RTPI). ${ }^{2}$

The main reliability, more efficient system monitoring, congestion reduction and external costs are highlighted as the reason for the introduction of RTPI systems. The cities that also recognized these advantages are Turin, Helsinki and London [8].

Dublin City Council is tasked with implementing the RTPI, as the Council has the power to approve decisions to carry out all technical works or street markings. Dublin Bus sends data to the City Council in support of RTPI. The system currently processes real-time information for approximately 1,000 stops and aims to increase the ability to process data to 5,000 stops [9].

Real-time public transport information, such as showing the actual time of arrival of buses to the bus station, can help public transport users with greater precision of travel planning. Real-time access to information can be achieved in several ways, for instance, access from where the user is located, or other available ways that suit the user more. Simple ways to obtain real-time information are to enter the bus station number (Figure 1) on Dublin bus's website or the application of the Dublin Bus app or Transport for Ireland Apps. Also, real-time search for information can be achieved by entering the bus station number, bus route, bus station address, and searching by map on Dublin Bus boarding pages. An additional option to receive information is via SMS messages, which can help visually impaired people with the ability to read information using voice programs [10].

\footnotetext{
1 DTA - Dublin Transport Authority

2 RTPI - Real-time passenger information
} 

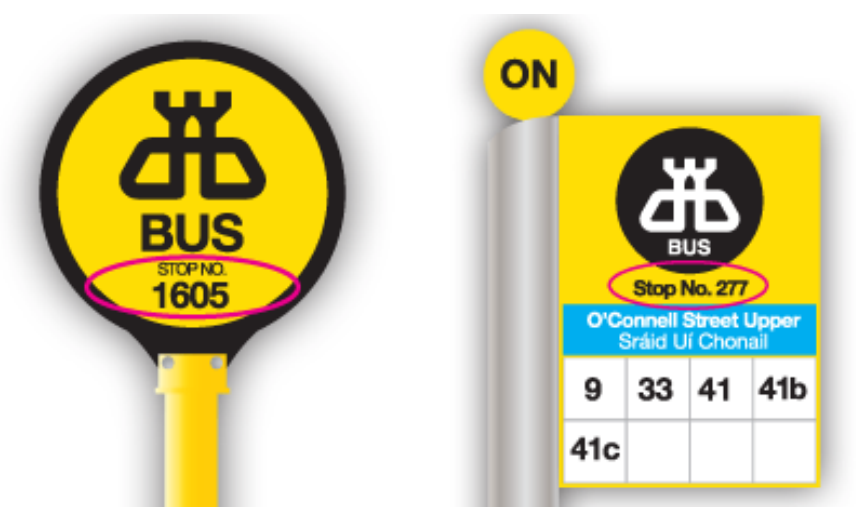

Figure 1 - Number of the bus station in Dublin

Source: [10]

Access to real-time information can also be achieved through street markings, and there are around 500 in the centre and periphery of Dublin. The National Transport Authority coordinates sign monitoring in cooperation with Dublin City Council and Dublin Bus.

Automatic transmitters built into buses or GPS monitoring allow the bus arrival information system to operate, while the software predicts the arrival time at the next bus station. The control system then sends the information to the bus station's notification display, i.e. counting the minutes until bus arrival (Figure 2). The vehicle's location system is charged to update the data, which sends information at 30-second intervals, ensuring accuracy during the time of bus arrival shown on the notification screen. The reliability of the information is monitored by the National Transport Authority (NTA) to provide a better service [10]. 


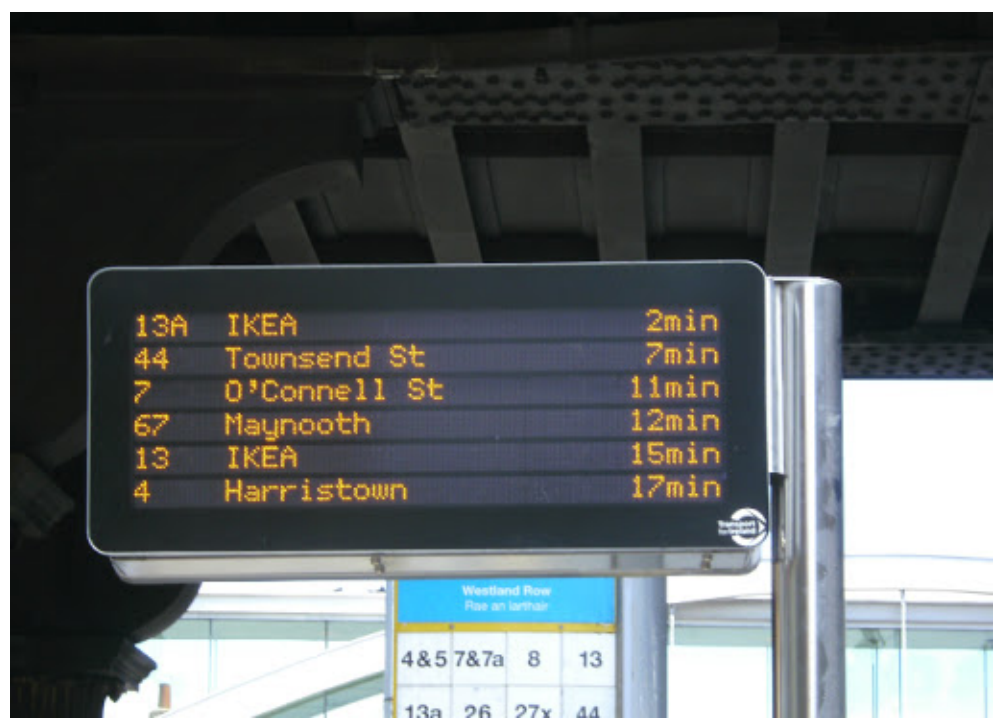

Figure 2 - Display of the RTPI system notification screen in Dublin Source:[11]

The reliability of the information may be affected by operational segments such as: (Bus, 2019)

$\diamond$ Technical problems,

$\diamond$ Downtime,

$\diamond$ Closed roads,

$\diamond$ Mechanical problems,

$\diamond$ Traffic congestion.

Dublin's public bus service serves around 1000000 passengers and the bus network consists of a fleet of 1000 buses and around 5000 bus stops. Dublin Bus is used for $70 \%$ of Dublin's total bus routes during peak hours. Buses have a much more varied direction of movement than trains and trams and have a much higher number of stops and a higher risk of getting into traffic jams. Unforeseen problems such as mechanical problems or road closures can affect the quality of public transport services. The real-time information display system is designed to respond to service disruptions, such as traffic jams, which increase waiting times.

In order to reduce the possibility of communication failures between the central server and the equipment on the bus, software support continuously upgrades through the Network Direct project, while the information is continuously updated.

RTPI predicts the expected bus arrival using the location the bus transmits, however if the bus remains in traffic jams the information at the bus station will adapt to the conditions set. 
For the sake of high costs, the notification displays are not distributed at all bus stations, their locations are determined depending on the place that can provide information to the highest number of passengers, for example [10]:

$\diamond$ number of bus services and the number of existing and potential passengers using stations every day,

$\diamond$ locations near crucial services such as shopping districts or essential public buildings,

$\diamond$ proximity to bus-marked lanes (QBC),

$\diamond$ proximity to major transport hubs.

\subsection{London - SCOOT (Split Cycle and Offset Optimization Technique system)}

As one of Europe's biggest cities, London faces problems such as large crowds of pedestrians at pedestrian crossings and reduced safety. In urban central London there are everyday situations where (like that of Bristol and some other British cities) pedestrians sometimes have to wait twice for a green light at a traffic light to cross a pedestrian crossing [12]. The purpose of the introduction of the $\mathrm{SCOOT}^{3}$ system for pedestrians was precisely to achieve a better and safer transition of pedestrians through pedestrian crossings without slowing down road traffic.

The SCOOT system for pedestrians has proved to be successful in managing urban traffic that reduces congestion in urban areas, both road and pedestrian traffic. The system implemented also additional elements for traffic management such as [13]:

$\diamond$ priority of the bus,

$\diamond$ traffic saturation controls based on feedback,

$\diamond$ detection of incidents,

$\diamond$ online saturation measurement,

$\diamond$ emissions of harmful gases in vehicles,

$\diamond$ priority of pedestrians.

The SCOOT system in London receives traffic flow information using 15000 detectors located in 3890 different locations with signals under SCOOT control. In 2014 counters were set up at 550 pedestrian crossings at more than 200 locations within 30 London boroughs [14]. Given the need for the growth of road transport, non-motorized transport and a higher proportion of pedestrian movement through the city, a challenge is created that would result in the optimization of traffic signals in favour of pedestrian traffic [13].

Urban areas with heavy traffic are facing problems such as crossing the road by large numbers of people. Also, an additional problem is sending a request by pedestrians to cross the road, and then crossing the road during the red light or giving up pedestrians to cross over a pedestrian crossing, which creates unnecessary delays [15].

3 SCOOT - Split Cycle and Offset Optimisation Technique system 
The SCOOT system contributes significantly to addressing these problems despite uneven pedestrian traffic and ensures that more pedestrians are crossing the pavement by optimizing crossing times. The system uses video cameras that count pedestrians waiting at a pedestrian crossing, and if the camera detects many pedestrians, the system approves the road crossing. However, if there is no one at the crossing or if someone presses the pavement crossing button and then goes to the red light or gives up, the system will give up on the green light.

An additional advantage of this system is the safety of pedestrians, so unlike older "pelican" crossings where the signals for crossing the pavement are located on the opposite side of the road, according to the new SCOOT system the signal is displayed above the pavement crossing button [15].

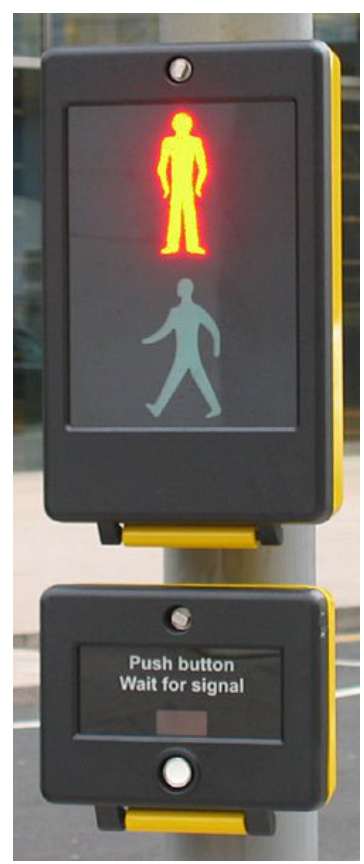

Figure 3 - Pedestrian SCOOT signalling

Source: [15]

The combined volumetric detection of pedestrians and SCOOT systems in London has implemented intelligent pedestrian crossings based on pedestrian density recognition and changes the lights at traffic lights accordingly.

Testing of intelligent technology for pedestrians began in 2014, after the release of the document "Safe London Streets - Our Six Road Safety Commitments" which aims to reduce the number of people killed and seriously wounded in London by 40 $\%$ by 2020 . 
On the average, the SCOOT system reduces the waiting time of vehicles in traffic by $12.5 \%$ and reduces the number of vehicles that have to be stopped while travelling through the transport network by $4.6 \%$.

The advantages of optimizing pedestrian traffic using SCOOT systems are [13]:

$\diamond$ pedestrians get the time it takes to cross the pedestrian crossing,

$\diamond$ improves road safety and comfort,

$\diamond$ detectors control the time of crossing of pedestrians via the pedestrian crossing,

$\diamond$ pedestrians' waiting for green light is reduced to a minimum,

$\diamond$ improves the efficiency of pedestrian crossings through pedestrian crossings at intersections,

$\diamond$ reduce vehicle delays,

$\diamond$ decrease the pedestrian downtime through a shorter cycle time.

\subsection{Stockholm (Congestion pricing)}

At the beginning of the $21^{\text {st }}$ century, Stockholm was marked by high traffic congestion, and it was necessary to find a solution to this problem. One way to prevent traffic saturation on major roads was to introduce charges for certain parts of the city or zones where vehicle entry charges would be made. Stockholm's traffic congestion charging zone was modelled on London, and the introduction of such a billing system was the second example in Europe [16].

The fee for entering the vehicle into the congestion zone was in the testing phase for seven months in 2006. Furthermore, it was fully introduced in 2007. The result of the implementing fee in the urban area was a reduction of $\mathrm{CO}_{2}$ emissions by $14 \%$ or 25000 tons per year in the coming years, i.e. a reduction in transport by $22 \%$ or 100 000 passengers per day with a reduction of travel time by 30-50\% [17].

The Swedish Road Management (The Vägverket) ${ }^{4}$ is the responsible body for managing fees and its systems, while IBM participated in the project as the main contractor in charge of the design, development and operational implementation of the system. IBM has developed a system based on wireless RFID technology, whose devices are supplied by Norwegian company Q-Free, which is one of the leading companies for the delivery of toll devices. The system uses a toll charger and traffic signalling device in combination with an operating system provided by IBM.

Payments can be made in several ways, such as contactless billing, or using an electronic toll device that directly charges the user's account. Video cameras are also used to control tolls, which can record the number of license plates using the ANPR 5 system, i.e. the number of road tolls and identify vehicles without toll devices, thereby serving as evidence against non-payers [16].

\footnotetext{
$4 \quad$ The Vägverket - Swedish Road the Administration

5 ANPR - Automated Number Pay Image copyright Getty Images Image
} 
The user charge options for the traffic saturation zone are as follows [18]:

$\checkmark$ direct debit ("autogiro") - allows the automatic debit of the user's bank account or offers the possibility of combining with an electronic invoice,

$\diamond$ electronic invoice ("e-invoice") - the possibility of using Internet banking,

$\checkmark$ payment - at the end of each month the Swedish Transport Agency (Transportstyrelsen) ${ }^{6}$ sends a payment card to the owners of vehicles registered in Sweden.

Using transmitters built into vehicles increases the reliability of receiving signals and reduces the cost of background operations concerning non-option billing systems. Also, the application of the transmitter makes it easier to charge fees for passing through a traffic-saturated zone by automatically charging the account after reading the device [17].

The exemption from the charging of the fee for the passage of the saturated traffic zone shall include emergency vehicles, buses, diplomatic vehicles, persons with disabilities, military vehicles, hybrid or electric vehicles, motorcycles and mopeds and vehicles registered in other countries. Toll ramps are equipped with plate number identification cameras that record the identity of passing vehicles.

Congestion zones consist of toll cordons within the city reducing traffic through bottlenecks located on the arteries leading into the inner-city centre. The area includes the centre of Stockholm [19].

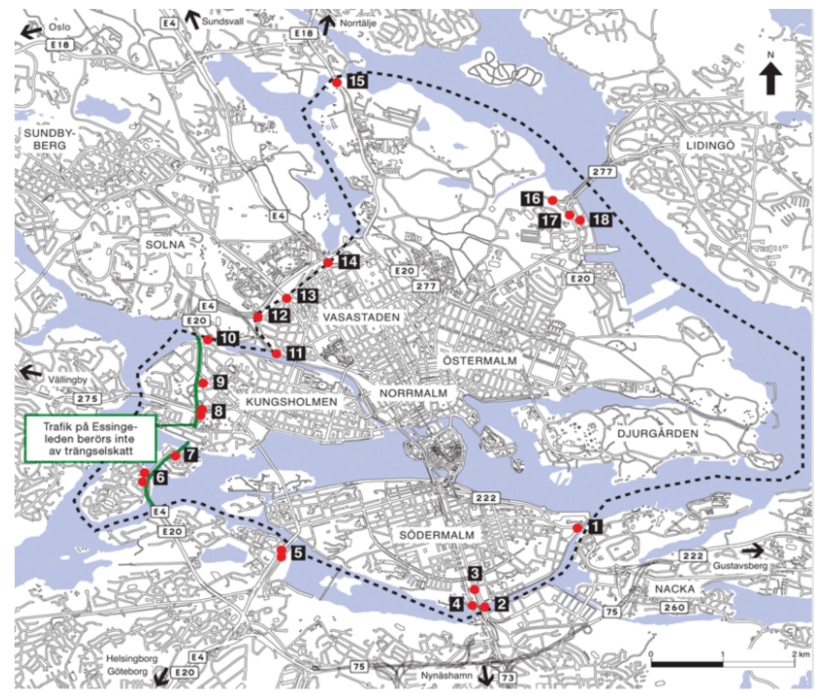

Figure 4-Display of checkpoints established at all entrances to the central area Source: [19]

$6 \quad$ Transportstyrelsen - Swedish Transport the Agency 
Eighteen electronic checkpoints have been established at all entrances to the congestion zone, while fees apply to the entrance and exit of the area.

Traffic decreased by approximately $20 \%$ using the toll zone, equivalent to 100000 passages over the charge cordon during the congestion period each day. The reduction of congestion of main roads is $30-50 \%$, and at the same time, the emission of harmful exhaust gases within the city is reduced by $10-14 \%$. Variability in travel times also decreased significantly. More than one half of drivers opted to bypass the toll zone using alternative routes, while other drivers who chose to avoid paying a fee used a period in which the pass-through zone was not charged.

Net earnings from fees are approximately 65 million Euros per year. In addition to revenue, the toll zone has a positive impact on [19]:

$\diamond$ shorter and more reliable travel times,

$\diamond$ lower greenhouse gas emissions,

$\diamond$ favourable impact on health and the environment,

$\diamond$ increased traffic safety,

$\diamond$ increased revenues from public transport.

Calculations [19] showed that the introduction of a system for charging fees for entering traffic congestion zones did not adversely affect people on lower incomes. Moreover, they benefited from the introduction of toll zones. People with higher incomes living in the central part of the city pay higher fees by implementing this system than residents of other urban areas.

Through the testing phase of toll zones, items that needed to be changed or improved were observed [17]:

$\diamond$ expanding the number of shops where payments can be made,

$\diamond$ the abolition of the requirement for the use of transponders in cars for highquality car recognition cameras at the entrance to the zone,

$\diamond$ enabling the direct debit payment system to be accessible to all drivers, whereas previously exclusively transponder vehicles could be linked to a direct debit payment system,

$\diamond$ extension of the payment timeframe from 14 to 30 days.

\subsection{Vienna - example of parking management}

The management of parking lots is considered a useful tool for managing transport demand. Also managing parking areas can reduce vehicle traffic or unburden roads in certain areas. Given the possibilities of application based on place and time, the introduction of a parking management system reduces parking requirements by $20-40$ $\%$. Also, as a significant result of the application of this system is the change in the behaviour of individual road users. Increasing demand for other modes of transport, increased use of urban public transport, changing routes or shortened stays reduce traffic congestion and indirectly the pollution of the environment by lower emissions of harmful exhaust gases [20]. 
The management of the parking space in the city of Vienna began in 1994. The purpose of the rollout was to reduce traffic in urban districts and reduce parking in the long term. It also sought to provide more parking spaces with better parking conditions for people living near the parking lot.

The increase in the number of vehicles, with the growing lack of parking spaces, has forced the city of Vienna to take measures to develop a parking space management plan. It also seeks to restore public space while improving parking space for the occupants of nearby buildings and short-term parking users. Therefore, due to the situation with parking, a large part of the population began to use alternative means of transport, bicycles and urban public transport, which significantly contributed to the quality of life and the protection of the environment [21].

In 1994 the City Council of Vienna accepted the "Traffic concept", and in 2003 the model continued to be perfected in "Transport Master Plan Vienna 2003" to promote urban public transport, pedestrian and cycling transport. The improvement of the city's transport system was followed by the installation of parking garages that were used on the principle of the "Park and Ride" system or parking near public transport allowing vehicles to be abandoned and to continue travelling through the city by public transport.

In 1994, the Vienna Commission developed a parking management system except for large zones for short-term parking while the project began to be tested as a shortterm parking zone in the $1^{\text {st }}$ district.

The objectives of the parking space management system were [21]:

$\checkmark$ reducing car traffic and harmful environmental impact,

$\diamond$ better situation for parking and for public transport (by reducing unauthorized parking),

$\checkmark$ improved availability of freight and delivery;

$\diamond$ renewed public space and improved road safety,

$\diamond$ higher revenues for improving urban transport,

$\diamond$ improvement of the residential urban environment.

For quality parking space management, it was necessary to transform the districts of the city or turn much of the district into short-term parking zones. The short-term parking area includes districts $1^{\text {st }}$ to $9^{\text {th }}, 15^{\text {th }}, 20^{\text {th }}$ and parts of the $12^{\text {th }}, 14^{\text {th }}, 16^{\text {th }}$ and $17^{\text {th }}$. District 15 or the broader area of Stadthalle has a specially regulated parking. Short-term parking zones are parking spaces where parking time is limited with special regulations. 


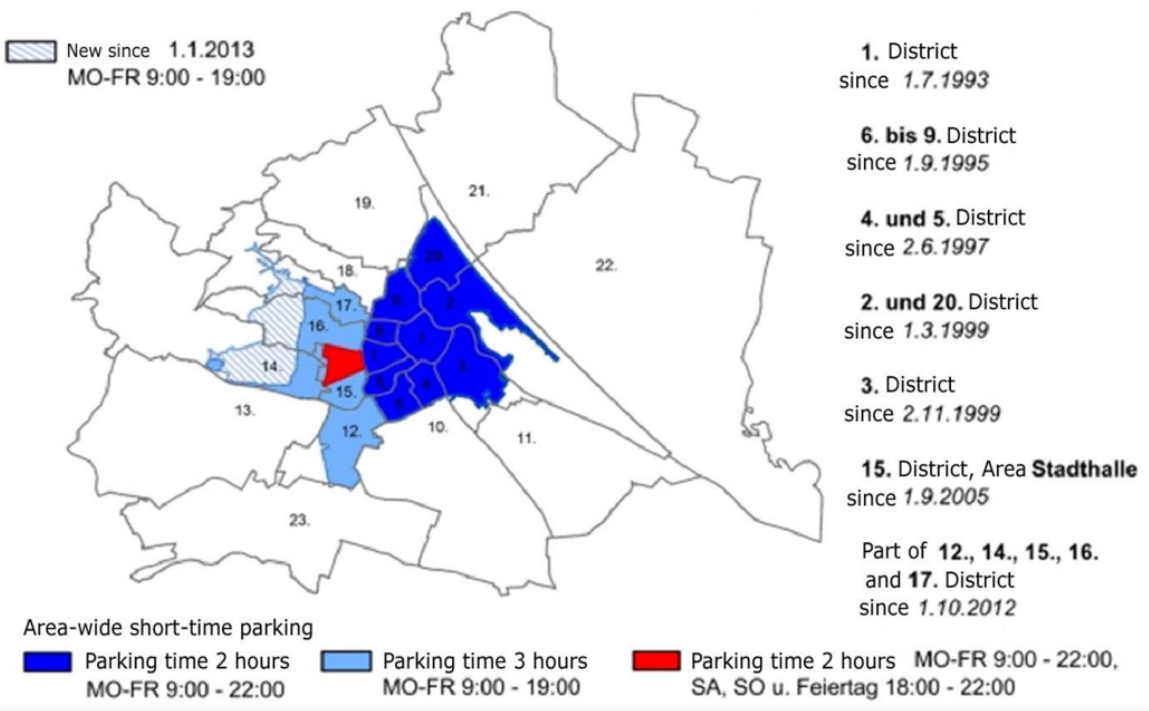

Figure 5 - Parking zones in Vienna Source:[21]

Since 2010, the decision to increase the cost of parking from 1.20 Euros per hour to 2 Euros per hour has led to less demand for parking in a short time.

Table 1 - View of Parking Prices in Vienna

\begin{tabular}{|l|l|l|}
\hline \multicolumn{2}{|l|}{ Parking prices } \\
\hline Parking voucher color & Parking time & Rating \\
\hline Purple & 15 mins & No charge \\
\hline Red & 30 min & 1 \\
\hline Blue & 1 hour & 2 \\
\hline Green & 1.5 hours & 3 \\
\hline Yellow & 2 hours & 4 \\
\hline
\end{tabular}

Source: [21]

Residents living in certain areas of short-term parking have been offered long-term parking permits. The right to obtain a long-term parking permit is exercised by the residents of that zone, and the request for parking with a sticker can be sent online or 
directly to the municipal district office. Businesses and crafts have the option to request a temporary parking permit. All revenues generated through parking management are intended for the Vienna transport system and must be used purposefully for the improvement of the city's public transport garages, the development of traffic safety measures, etc., while the principle of parking management policy is that the costs of traffic are borne by traffic users instead of the society as a whole [20].

Table 2 - View of the objective, orientation, data used and parking management results

\begin{tabular}{|c|c|c|c|}
\hline Goals & Orientation & Data used & Showing \\
\hline $\begin{array}{l}\text { Reduce } \\
\text { traffic in the } \\
\text { district, } \\
\text { Improvement } \\
\text { of parking } \\
\text { spaces } \\
\text { for local } \\
\text { residents, } \\
\text { Improving } \\
\text { the } \\
\text { accessibility } \\
\text { of freight } \\
\text { vehicles. }\end{array}$ & $\begin{array}{l}\text { Parking } \\
\text { space } \\
\text { management: } \\
\text { limited } \\
\text { parking } \\
\text { times and } \\
\text { parking fees }\end{array}$ & $\begin{array}{l}\text { Assessment } \\
\text { of the } \\
\text { objectives } \\
\text { for the } \\
\text { Transport } \\
\text { Master Plan } \\
\text { of the City } \\
\text { of Vienna } \\
2013\end{array}$ & $\begin{array}{l}\text { In the parking departments of } \\
\text { districts } 1-9 \text { and District } 20 \text {, the } \\
\text { model share targets for car traffic } \\
\text { have already achieved } \\
\text { very good results in districts } 14 \text { to } 19 \\
\text { Situations for residents significantly } \\
\text { improved thanks to the increase } \\
\text { in parking in working hours; } \\
\text { management of parking in the inner } \\
\text { districts of the city up to } 22 \text { hours } \\
\text { Before the introduction of parking } \\
\text { management, the average time within } \\
\text { the belt was } 6 \text { to } 8 \text { hours. Now it } \\
\text { is } 1 \text { to } 2 \text { hours decrease in parking } \\
\text { utilisation up to } 30 \% \text { after the } \\
\text { introduction of parking management, } \\
\text { mainly due to the decline in the } \\
\text { number of cars that do not have } \\
\text { Vienna plates } \\
\text { Significant reduction in the search for } \\
\text { free parking spaces and the number } \\
\text { of improper parking }\end{array}$ \\
\hline
\end{tabular}

Source: Created by authors based on data [21] 


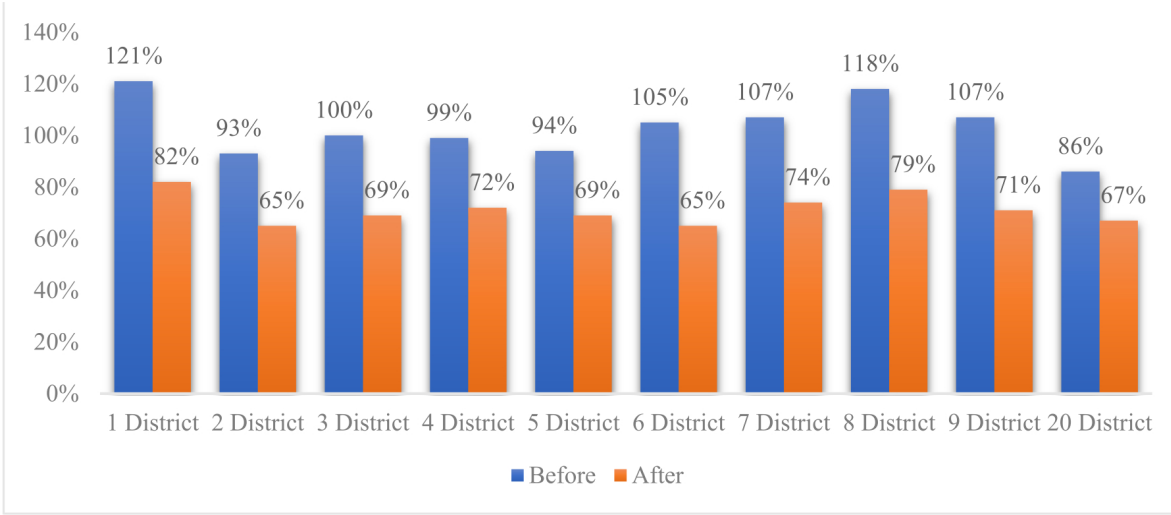

Figure 6-Reducing the utilization rate of parking spaces in the morning Source: Created by authors based on data [21]

Graphs 1 and 2 present a decrease in the use of parking spaces in the morning and afternoon hours, which means a positive development resulting from the parking space management system in the city of Vienna. The largest oscillation occurs in the morning in District 6, while the smallest one in the afternoon and evening in the District 20.

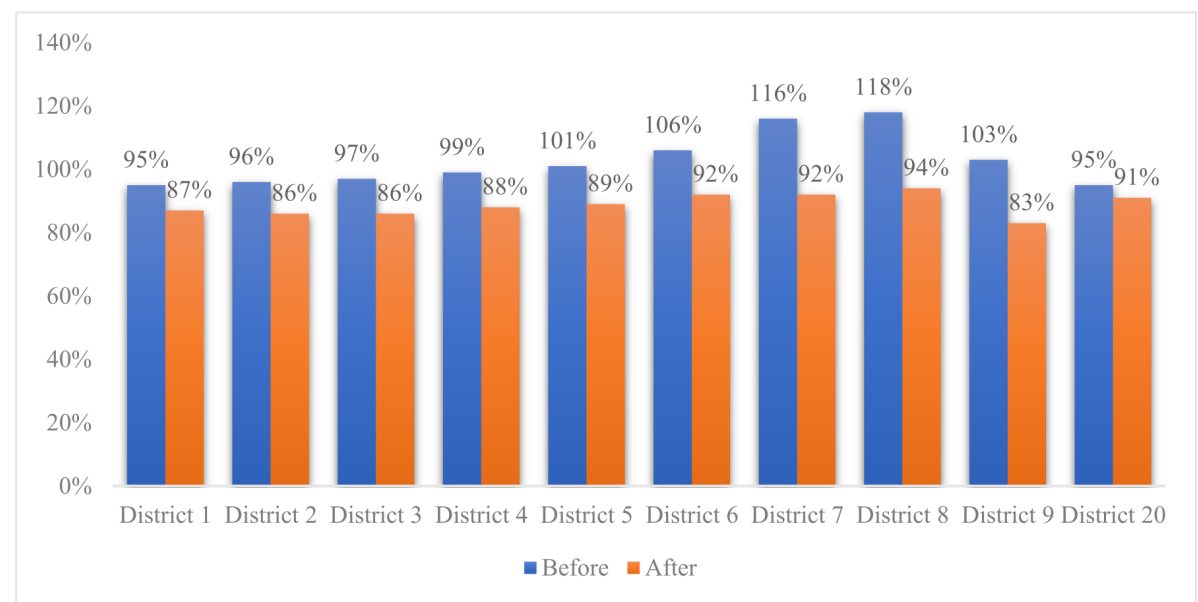

Figure 7 -Reducing the utilization rate of parking spaces in the afternoon Source: Created by author based on data [21] 
In order to take full advantages from the implementation of the system, for the city of Vienna it is necessary for the traffic management model to be monitored by other measures and policies such as: [20]

$\diamond$ increase in short-term parking charges,

$\diamond$ improving sufficient capacity and high quality of public transport,

$\checkmark$ introduction of accessible annual tickets for public transport,

$\diamond$ development of "Park \& Ride" system facilities,

$\diamond$ use of municipal residential garages,

$\diamond$ changes in the building regulations to reduce minimum parking requirements.

\section{The importance of the traffic management system for the development of urban mobility}

„The existing technologies implemented in public transport are smart card, e-vehicles, autonomous vehicles, software for planning an organizing public transport network, data collecting devices, software for data processing, various real-time information systems, smart public transport stops, etc. The existing technologies implemented in parking facilities and parking management are: apps for optimizing available car parks, devices and sensors for counting available on-road parking spaces, smart cards for charging parking fees, software for parking management, etc.” [22]

In the transport sector, former thinking about solving mobility problems by increasing the capacity of roads and other infrastructure has been replaced by "modern" solutions such as the application of information and communication technology, which has proven to be a much better solution especially in optimizing the transport system. Smart mobility is applied today in many countries while it is most prevalent in developed and densely populated areas [22].

Addressing urban mobility in cities using ITS would mainly include public transport, pedestrian safety, reduce traffic congestion and accidents as well as parking solutions. ITS use traffic and mobility management solutions to provide residents with and bring them closer to various forms of transport [4].

The importance of traffic management in urban areas is most evident through the "smart" solutions that ITS enable. For example, features such as public transport management, route information, safety and vehicle control have the greatest advantages in densely populated cities. Cities that implement such systems in terms of solving mobility problems are most often called "smart cities".

Route optimization technology that analyses data in real time is implemented in public transport management, which increases the quality of service. Urban transport users also find it easier to plan, as real-time information improves the accuracy of predicting the arrival of public transport, which is a feature of the "smart city".

According to [4], route information is the aspect that most disrupts the smart transport system. Drivers and other road users benefit greatly from the smart transport 
system regarding real-time information that provides insight into the current state of the roads, which affects a better choice of the route or mode of transport. Furthermore, users can check the duration of the trip with the immediate suggestion of alternative routes or modes of transport if traffic is congested on a given section.

Although the implementation of smart technologies in the transport sector has a significant impact on increased safety and environmental impact, the implementation of ITS systems is largely dependent on budgets and funding. However, expectations for the further development and use of these technologies are high given the results and the growing awareness of the use of new technologies for the purpose of transport optimization. With the development of information and communication technology, i.e. the Internet of things, smart cards, cloud computing, mobile devices, data collection software, there are various applications in the management of public transport and parking which lead to a higher quality service due to greater capabilities and performance of the transport system in general.

Over the past few years, various opportunities for easy access (mobile applications, web widgets, and self-service kiosks) to mobility services have appeared on the mobility market. For example, applications on smart phones provide information about the current state of traffic, public transport or parking and can serve as a means of payment. Also, for the purpose of faster and easier payment in public transport, smart cards have been introduced offering users more payment options, as well as the possibility of using one card for several services [22].

\section{Conclusion}

The rapid expansion of cities and the number of urban inhabitants have created various problems, the most prominent of which are traffic congestion and environmental pollution. In addition to environmental pollution caused by traffic, the problem is further exacerbated by traffic congestion. This issue has been reflected in the efficient development of urban mobility which directly affects the quality of life in cities.

With today's need for mobility, efficient urban transport is one of the primary tasks of cities. Given that urban transport affects economic development and vice versa, it is inconceivable that a functional city is sustainable without urban mobility. The main challenge for improving the flow of traffic in urban areas is to reduce the large number of individual vehicles using alternative means of transport (trams, buses, railways, bicycles, etc.). In many European cities with developed bicycle infrastructure, this problem has been reduced precisely because of the use of bicycles for shorter trips which is reflected in the traffic situation. However, the biggest turning point can be achieved by urban transport which seeks to get closer to users through various information and communication technologies that significantly increases the quality of service.

Examples of good traffic management practice can serve as an analysis or assumption that the implementation of a smart system would reflect the current 
problems of the city with similar conditions and coverage of the problem. Challenges are common to most cities, so examples of smart systems implementation can help to reduce the negative impact of traffic and improve the quality of urban street use.

The application of ITS is a very expensive process and requires the commitment of the city leadership with the smooth running of other logistics projects. Sustainable urban transport is a difficult task, especially since transport problems cannot be solved only by upgrading or increasing the transport infrastructure but it is necessary to optimize the existing one with the application of smart systems. Smart traffic management systems are already improving traffic flow, so with further development it is very likely that they will play a significant role in traffic optimization and sustainability in the future.

\section{References}

1. Papageorgiou, M., Ben-Akiva, M., Bottom, J., Bovy, P. H.L., Hoogendoorn, S. P., Hounsell, N. B. and Kotsialos, A. (2007) Chapter 11 ITS and Traffic Management. Handbooks in Operations Research and Management Science, 715-774.

2. Hamilton, A., Waterson, B., Cherrett, T., Robinson, A. and Snell, I. (2013) The evolution of urban traffic control: changing policy and technology. Transportation Planning and Technology. 36(1), 24-43.

3. Maršanić, R. and Krpan, L. (2015) Contemporary Issues of Urban Mobility. International Journal Vallis Aurea. 1(2), 5-14.

4. Cohen, E. (2020) How Smart Transportation Solves Urban Mobility Problems. Available from: https://blog.mobility.here.com/smart-urban-transportation [Accessed: 17th June 2020].

5. Study on Planning for Pedestrian. (2002) Available from: https://www.pland.gov.hk/pland en/p_study/prog_s/pedestrian/stage1_pubcon/english/e_content.htm [Accessed: 27th June 2020].

6. Car-free zone, strolling zone and bicycle path network|CIVITAS. (2013) Available from: https:// civitas.eu/measure/car-free-zone-strolling-zone-and-bicycle-path-network [Accessed: 18th June 2020].

7. Bošnjak, D. and Ižaković, I. (2017) Urbana mobilnost. Paragraf. 1(1), 77-94. Available from: https://hrcak.srce.hr/188420 [Accessed: 18th June 2020].

8. Caulfield, B. and O'Mahony, M. (2003) Real-time passenger information: costs and benefits. Available from: https://pdfs.semanticscholar.org/5786/e2064edc83904f06f98b499a8c8c21e20 e2b.pdf.

9. Pradip, K. S. and Jain, A. K. (2018) Intelligent transport systems. In: PHI Learning Private Limited. New Delhi, 287. Available from: https://books.google.hr/books?id=9Jk-DwAAQBAJ\&pg=PA28 $7 \& \mathrm{lpg}=\mathrm{PA} 287 \& \mathrm{dq}=\mathrm{The}+$ provision $+\mathrm{of}+\mathrm{on}+$ street + passenger + information $+\mathrm{via}+$ real + time + passe nger+information;+a+case+study+of+Dublin\&source=bl\&ots=URAjvqB4Ca\&sig=ACfU3U218 mNfSA97F-hlLRJ94eaPehBLyA\&hl=en\&sa=X\&ved [Accessed: 4 June 2020].

10. Dublin bus. (2019) RTPI FAQs - Dublin Bus. Available from: https://www.dublinbus.ie/RTPI/ RTPI-Help-Page/ [Accessed: 4th June 2020].

11. Dublin City. (2019) Available from https://www.kentstainless.com/industries-served/public-realm/ dublin-city-council [Accessed: 4th June 2020].

12. Davies, J. (2012) Using scoot multi-nodes to reduce pedestrian delay at dual crossings in Bristol. Bristol. Available from: http://www.jctconsultancy.co.uk/Symposium/Symposium2012/ PapersForDownload/Jackie Davies Using SCOOT multi nodes to reduce pedestrian delay at dual crossings in Bristol.pdf [Accessed: 4th June 2020]. 
13. TRL. (2014) Pedestrian SCOOT Systems. Available from: https://trl.co.uk/projects/pedestrianscoot-system [Accessed: 4th June 2020].

14. TfL to launch world-leading trials of intelligent pedestrian technology to make crossing the road easier and safer - Transport for London. (2014) Available from: https://tfl.gov.uk/info-for/media/ press-releases/2014/march/tfl-to-launch-worldleading-trials-of-intelligent-pedestrian-technologyto-make-crossing-the-road-easier-and-safer [Accessed: 4th June 2020].

15. London to trial,,intelligent " pedestrian crossings. (2014). Available from: https://newatlas.com/ pedestrian-scoot/31154/ [Accessed: 4th June 2020].

16. Road Traffic Technology. (2003) Stockholm Congestion Charge - Verdict Traffic. Available from: https://www.roadtraffic-technology.com/projects/stockholm-congestion/ [Accessed: 7th June 2020].

17. C40. (2011) Available from: https://www.c40.org/case_studies/stockholm-to-introducecongestion-charge-trial-cut-co2-by-14-traffic-by-25 [Accessed: 7th June 2020].

18. Paying and notification of congestion tax - Transportstyrelsen. (2020) Available from: https:// www.transportstyrelsen.se/en/road/Congestion-taxes-in-Stockholm-and-Goteborg/paying-thecongestion-tax/ [Accessed: 7th June 2020].

19. Stockholm "s Congestion Pricing. (2014) Available from: https://www.toolsofchange.com/ userfiles/Stockholm Congestion Pricing - FINAL 2014.pdf [Accessed: 7th June 2020].

20. Learning from Vienna: Effective Parking Management - Vienncouver. (2015) Available from: https://www.vienncouver.com/2015/10/learning-from-vienna-effective-parking-management/ [Accessed: 14th June 2020].

21. Catalogue on Parking Management Solutions PUSH\&PULL-"Parking management and incentives as successful and proven strategies for energy-efficient urban transport". (2015) Available from: https://www.eltis.org/sites/default/files/trainingmaterials/pp_pm_catalogue_01062015_final.pdf [Accessed: 27th June 2020].

22. Brcić, D., Slavulj, M., Šojat, D. and Jurak, J. (2018) The role of smart mobility in smart cities. Road and Rail Infrastructure $V, 1601-1606$. 
